This is an electronic reprint of the original article. This reprint may differ from the original in pagination and typographic detail.

Author(s): Fortunati, Leopoldina; Taipale, Sakari; Farinosi, Manuela

Title: $\quad$ Print and online newspapers as material artefacts

Year: $\quad 2015$

Version:

Please cite the original version:

Fortunati, L., Taipale, S., \& Farinosi, M. (2015). Print and online newspapers as material artefacts. Journalism, 16(6), 830-846.

https://doi.org/10.1177/1464884914545439

All material supplied via JYX is protected by copyright and other intellectual property rights, and duplication or sale of all or part of any of the repository collections is not permitted, except that material may be duplicated by you for your research use or educational purposes in electronic or print form. You must obtain permission for any other use. Electronic or print copies may not be offered, whether for sale or otherwise to anyone who is not an authorised user. 


\title{
Print and online newspapers as material artefacts
}

\begin{abstract}
Traditional newspaper journalism is in a state of crisis and there have been several attempts to overcome this. Many discourses have reiterated the triumphal march of a digital revolution in newspaper journalism and anticipated the end of the print newspaper. This moment calls for an indepth analysis of reader habits of news consumption and use in order to understand the audiences for journalistic output and their relationship with the journalistic objects. In this study, we adopt a multi-method approach, integrating 1) qualitative content analysis of student essays dealing with the physicality of printed and online newspapers; 2) ethnographic observation of the use practices of readers; 3) expert interview. The findings show that informants perceive print and online newspapers as objects with which they have a different experience and highlight the need to develop bridging strategies combining print and digital media in order to overcome the crisis facing printed news media.
\end{abstract}

Keywords: print newspaper, online newspaper, readership, gestures, postures, use practices, emotion, ritualization, material objects

\section{Introduction ${ }^{\mathrm{i}}$}

To date, many attempts have been made to understand how print newspapers can overcome their current profound crisis: declining sales, scandals, and the rise of the Internet; as well as how print journalism can renew itself and build a possible future. Over the last two decades, the online world has launched a strong assault on print journalism, proving more attractive to readers than the print world. Online newspapers have challenged print with the full strength of the Internet. In comparison 
with print journalism, online journalism includes many value-added services and functions, such as social and mobile media.

This crisis can be attributed to inadequate understanding of the potential of new media as well as new challenges it poses to traditional print newspapers. In addition, media groups who own both print and online newspaper businesses have paid little attention to current analysis of the economic situation of online newspapers (e.g. Schiff, 2003). For many years these media groups have made a loss, many are still in search of revenues today as the great fragmentation of the business models applied and the wide cross-cultural differences between these business models show (Bleyen and Van Hove, 2007). It follows that a faulty business model has also been applied by some traditional media groups declaring the end of the print edition and keeping only the online edition. The history of development of the Internet and its influence on print newspapers has been actively studied. For example, van der Wruff and Lauf (2005), Bokowski (2004), Deuze (2011) and Domingo (2008) have shown how online newspapers have been fundamentally a near transposition of print newspapers to the Internet. The fear of publishing houses that print newspapers would be cannibalized by online newspapers was overridden in the hope of attracting more readers online. What was completely lacking in that business model was a clear vision of the advertising which against all expectations was very slowly colonizing the Internet (Küng, Picard and Towse, 2008). Hence, media groups spent revenues gained from adding inserts (e.g. volumes of encyclopaedias, dictionaries, book series or DVDs) to print newspapers to support their unsuccessful Internet adventures. This strategy followed the business idea according to which these spin-off products could be efficiently commercialized through the purchasing power of the wide readership of printed newspapers.

Many studies address how the journalism world has reacted to the Internet and how newsrooms have been restructured (e.g. Fortunati et al. 1999). According to Barnhurst and Napoli (2011), print newspapers are clearly the product of industrial capitalism, while the present crisis of print newspapers is the outcome of financial capitalism which makes it all the more liquid. This shift 
from industrial- to financial-based capitalism also explains the change in the ideology of journalism and its role in society. For example, Colombo (2013) reminds us that while American media were almost all sympathetic towards the civil rights movement, today large sectors of the journalistic world are very far from being watchdogs for democracy. In fact, by taking up the wide debate on journalistic values, Sarrica et al. (2010) argue that alongside the role of a watchdog, journalists have increasingly adopted the role of a lapdog; sometimes alternating between watchdogs and lapdogs (e.g. Massing, 2012). This shift has contributed to the current crisis of print journalism, given that many potential readers, especially young readers, are disenchanted with newspapers. Although lapdog journalism has mainly been attributed to print journalists, it should also be extended to online journalists. This is because print and online journalists do not work on separate professional regimes. Hence, the priority in journalism studies should be to discover how print newspapers can extricate themselves from this crisis as they are continuously been perceived as the bulwark of journalism.

The aim of this study is to investigate reader news consumption habits and usage in order to advance our knowledge about the mistakes of the business model that has guided the activities of media groups on the Internet and inspires the present strategies for handling the crisis of print newspapers. The solution to this crisis is not technical, yet technological changes must be part of the picture. Previous literature has focused mainly on the comparison between the information features of print and online newspapers (e.g. Domingo et al., 2008). Looking at the identity as media of print and online newspapers has led researchers to focus on their functionality and consider people as users of their main functions. Unfortunately, this kind of approach has pushed researchers to neglect many divergent but important aspects of newspaper usage. Although this wave of research has produced important knowledge, these studies have often been too descriptive and limited in their scope to elucidate possible ways of overcoming the crisis facing the journalistic world. 
For this reason, we have decided to adopt a completely different approach. We chose to investigate print and online newspapers as material objects. Furthermore, we investigated what people do with these objects ${ }^{\mathrm{ii}}$.

The rest of the article is structured as follows. Section 2 presents the theoretical framework of the study and the research questions are detailed in Section 3. Research material and methods used in the study are described in Section 4, and the results are presented in Section 5. The final section discusses the results with reference to the research questions. The article ends with conclusions, reflections on the strengths and weaknesses of the study and on future directions for research on this topic.

\section{Theoretical framework}

This study investigated the physicality of print and online newspapers as objects. We have drawn on theoretical work on the micro-sociology of objects, following the examples of Douglas and Isherwood (1979) and Miller (1998). The ethnography of media, as a method of investigation, has in part responded to the need to understand media as objects (e.g. Casetti, 1995). The biography of technological objects (Turkle, 2007), technological autobiographies (Wyatt et al., 2000), and the history of news journalism (Barnhurst and Nerone, 2001) serve to describe media as objects. These studies, with the exception of Barnhurst and Nerone (2001), were conducted to investigate electronic technologies rather than print media, which also deserve more rigorous analysis.

Focusing on the materiality of these two objects led us to apply another theoretical framework, the so-called new or neo-materialism that explores how 'matter comes to matter' (Barad, 2003). New materialism represents the great return from words to things. New materialists ask not how discourses come to matter, but rather how matter comes to matter (Barad, 2003; 2007). They consider 'matter' in its twofold meaning: matter as the object of the research and matter as the concrete, material building blocks of the research object. The ways in which matter matters were first discussed by Alaimo and Hekman (2008), Bennett and Joyce (2010), Coole and Frost (2010), 
and later Bolt and Barrett (2013) as well as Dolphijn and Van der Tuin (2012). These authors advocated moving away from the study of representation, which applies 'words' to 'worlds' in a retrograde manner. New materialists are moved by a genuine interest in what people really do with information and communication technologies (Bennet, 2010). They do not deny the importance of the intangible, cultural and symbolic aspects of the processes of production and consumption involving the readership, but they call on the research community to focus on the physicality of the objects and their uses for building a wider vision of technological artefacts with the aim of obtaining a deep understanding of their identity. This theoretical framework is consistent with the theory of immaterial labour (Fortunati, 2007) and other critical developments in Marxist analysis (Fuchs, 2010; Ardvisson and Colleoni, 2012).

The triangulation of these different strands of theory - micro-sociology of objects, neo-materialism and immaterial labour theory - makes it possible to study print and online newspapers starting from their very essence as physical configurations. Furthermore, it enables us to begin by conceptualizing them as physical objects rather than as media, as well as considering their concrete uses, including for example reading styles, ritualization, gestures and postures, and emotions as experienced by users.

\section{Research questions and hypotheses}

The research questions addressed in this study are:

RQ1. What are the main physical characteristics of print newspapers and online newspapers as ‘objects’ perceived by users?

RQ2. What are the concrete uses of these two different types of newspaper?

We expected to find more characteristics and uses than those reported in previously published work, because our focus was on the physical object, rather than on its communication and information functionalities. This study is in line with the theory of uses and gratifications (Katz, Blumber and Gurevitch, 1973-74). With these two research questions, we aimed to advance understanding of 
how the crisis that has hit print newspapers can be overcome. The findings will provide insights for media groups and publishers, as well as for the research community.

\section{Method}

This qualitative research uses three methodological tools. The first tool is written essays collected from nineteen graduate students studying for a Master's degree in Multimedia Communication and Information Technologies at the University of Udine. The students involved were particularly sensitive to the issue of print and digital reading. Understanding attributes and functionality of new media is part of their course syllabus. Furthermore, this class participated in a project on The Print Newspaper in the University promoted by the National Association of Print Newspaper Publishers. This project aimed to stimulate each class to read print newspapers by delivering two print newspapers for each student for free (Il Corriere della Sera - the most widely read Italian newspaper - and Il Sole 24 Ore - the most widely read economics newspaper at European level). We invited the students to reflect on the following themes: the physicality of print and online newspapers including ownership, mastering of the objects, physical sharing of them; the variety of uses extending beyond the concept of these two objects as information tools; the ritualization of their purchase; their gestures and postures while reading them; the emotion evoked by the objects; memorization of news.

Students were not supplied with any other instruction on how to write about each theme. We were interested in their spontaneous thoughts. The decision to develop a research tool with this feature was dictated by the desire to have an instrument minimally influenced by the interaction between the researcher and the object of study. From a formal point of view, the texts obtained allowed more self-expression and spontaneity of content than a classical interview. Content analysis was used to assess the texts: they were broken down into discourse categories in order to capture the most relevant discursive frames (Altheide, 1996). 
The category frequencies were calculated and the most frequently occurring categories singled out. Those categories with relatively low frequency but possible importance to the clarification of some points of our analysis were also retained and discussed, as Silverman (1997) advises. This allowed us to trace a conceptual map of participants' experience of reading print and online newspapers and to build a classification scheme which provides an analytical description of the most important issues. This style of content analysis is a notably non-intrusive and flexible methodology (McNeill and Chapman, 2005).

The second research tool made use of ethnographic observations (c.f. Ostrower, 1998) which was supported by a content analysis grid. With this technique, twenty one observational cases were collected in various places: public libraries, train, houses, and at a newsstand. The observed items include: duration of the observation, age range of the persons observed, type of reading device, reading place and reading posture, use practices (reading alone or with another person, search of the most interesting titles, and so on), gestures, quality of gestures, distance between the body and the reading device. This applied observational method can be considered as a relatively unobtrusive strategy for data collection. It allows the researcher to observe subjects' behaviour without being actively part of the situation under scrutiny.

Finally, we conducted an expert interview (Della Porta, 2010; King and Horrocks, 2010) with Lia Lucato, a psychologist, psychotherapist and specialist in anti-gymnastics. The interview lasted five hours in total, over two sessions, and dealt with reading and writing on paper and electronic media. Some excerpts from her interview dealing with cognitive aspects of the research questions are included in our results. The expert interview research technique is considered the best way to get lots of in-depth or technical information on a specific topic in a short period of time. The interview with Lia Lucato also helped with the evaluation and validation of the content analysis of the student essays and the ethnographic observational study.

\section{Results}




\subsection{Print and online newspapers as material objects}

Print and online newspapers were described and perceived very differently by the students participating in the essay exercise. A print newspaper is considered as an object completed, finished in itself whereas an online newspaper is a service provided by Web 2.0. In its physical dimensions a print newspaper embodies the meaning and significance not only of its content but also of itself as specific object and of the overall experience of using it. Readers can take its measure at a glance, understand how large it is and roughly how many pages it has. Reading a print newspaper there is an experiential continuum, whereas online the reading experience is much more fragmented; users can only see the main page on the screen.

The experience of using an online newspaper is very different. First, users lose the sense of the totality of the object, as its physical dimensions are more evanescent and much less immediate. Second, online newspapers are one of the many resources offered by the Web. This means that they are third order objects: the first order object is the computer, the second order object the Internet and the online newspaper is the third order object. To access an online newspaper, one must first access the other two objects. Participant Alice A., one of the students, points out that:

"Print newspapers are autonomous in themselves while online newspapers are less autonomous because they depend also on supports; the battery, the power."

Third, print and online newspapers present a radically different manipulability: when holding a print newspaper one can handle the object in its entirety and immediately access the any chosen page. In contrast, with an online newspaper one only has access to one page at a time. This means that even access is much more fragmented and segmented compared with the print newspaper.

Fourth, differences in shape and consistency of print and online newspapers influence their content, since in general both information and knowledge are closely connected to the objects which convey them. The content of an online newspaper is also more fragmented that of a print newspaper. The bases in fact of information and knowledge are constructed inside an experience which is above all multisensory. The physicality and materiality of the print newspaper convey "a sense of authenticity 
and verifiability that the online newspaper cannot provide” argues the expert Lia Lucato. In conclusion, a print newspaper has a much stronger sensory appeal than the online newspaper. For this reason "it is also more difficult to attribute to online newspapers an economic value", as participant Enrico argued in his contribution to the essay study.

The differences in the materiality of these two objects also mean that readers have a different degree of control over them. While readers totally control the 'print newspaper' object, they cannot do the same with online newspapers. An online newspaper is housed in a 'universe' which belongs to somebody else - the media groups - and requires other devices to function (e.g. a computer with Internet access, sockets and perhaps also a printer complete with toner). The ability to manipulate completely a print newspaper gives readers a greater sense of mastery of that medium which, for example, leads some people to use their finger to point at the line they are reading. This gesture is totally absent from the reading of online newspapers regardless of the medium used to access the newspaper (smartphone, tablet, laptop), but may be replaced in the desk PC by pointing and selecting text with a mouse cursor.

Print and online newspapers also engender a different sense of ownership in their readers. Print newspapers are bought and possessed, while online newspapers typically are not. Although the cost of a single copy of a print newspaper is not high, towards the end of the month this cumulative expense becomes relevant.

"People attribute to this action [print newspaper purchase] even a higher and more intense value, precisely because there it is also a financial choice.” (Francesca)

As readers pay for a printed newspaper, they can interact with it as they want (for example by cutting out articles that they want to keep). People can also give or lend their print newspaper to somebody else as they choose. In contrast, when readers do not own an online newspaper, they can only read it. This means that: 
“... because of their physical supports, online newspapers such as PC, tablet or smartphone, are considered personal, in contrast to a print newspaper which can easily be transferred to others.” (Mirko)

Although print and online newspapers are designed to last one day, since the previous day's newspaper becomes social memory - which is a completely different item - the real life of print newspapers makes strange paths. With regard to this, participant Serena writes that:

"The print newspaper can be something that lasts. I have kept newspapers for years (if they had articles that interested me) until the space at home was suddenly reduced and I had to throw away a lot of them. I realized that I do not like to throw away print newspapers. I also do not like to reuse them to protect the furniture when the walls are being painted. The only print newspaper that I would use for this is the free press that lasts much less than a day: in general only the duration of a journey or a little more, if they include a sudoku."

The dimension of time - duration - is connected to that of space, which in many cases manifests itself as a limitation. The problem of space pointed out by Serena is faced in many homes. Many people do not have time during the day or the week regularly to read the newspapers and they keep them for future reference. Others collect interesting articles as newspaper clippings. Gradually the space in their house is reduced until the time when either they or the newspapers must leave the house. The same mechanism applies to books. With increased economic prosperity after the Second World War, books arrived in many houses and during the following decades they accumulated in the shelves and on the floor. This fact has created problems of coexistence between the inhabitants of the house and the books, as Baron argues in her forthcoming book Words Onscreen: The Fate of Reading in a Digital World.

5.2 The variety of reading styles and uses of print and online newspapers

Like any other object, print newspapers have a form. As Barnhurst and Nerone (2001: p. 3) argue, the form is: 
"the persisting visible structure of the newspaper, the things that make the New York Times, for example, recognizable as the same newspaper day after day although its content changes.” This form varies according to the layout, design, illustration styles, schemes of departmentalization etc., but more importantly it heavily affects readers.

While the form of print newspapers is definite, stable and tangible for readers, the form of online newspapers is more flexible owing to Web 2.0 tools that enable more dynamic and interactive structure as the following extract from participant Mirko’s essay shows:

“... you can place links within the article that lead to the news source or that can provide insights into some parts of the article with other pages of explanation or, with the system of tags, the reader can find all the news about a character involved in the story, even information unrelated to the original story.” .

One illustration of the relative inflexibility of print newspapers is that comparatively large print newspapers are not designed for easy reading on the move. Their dimension often exceeds that of the seat of a train, bus, or aeroplane. To read them users have to fold the paper, which reduces the visible surface. It can be argued that that the form of print newspapers responds to the needs of a world that was less mobile than the contemporary one. Reading print newspapers is more comfortable, albeit not problem-free, when one is seated in an armchair or at table. For example, participant Alberto writes:

"In the case of very large newspapers (such as Il Sole 24 Ore), if you want to read it on a table, reading the news in the high part requires you to physically operate in two ways: either you get closer to the page (e.g. by bending your back) or you bring the page close to you (e.g. by lifting it from the table). Given that a print newspaper is lightweight and can be folded, it is precisely the second operation that is used more often."

The print newspaper, however, allows much more sharing of the news and discussion with other members of the family, friends or acquaintances who are co-present. Thus the reading of print newspapers at home and in public spaces provides an occasion to share opinions directly with 
others and to find face-to-face company. The reading of online newspapers on smartphones or tablets is less immediate in this regard, online newspapers allow asynchronous sharing of the information with Internet users, for example, on social networks. By contrast, in many cases reading the print newspaper becomes a pretext for chatting with someone who is co-present.

The form of a newspaper also, of course, influences the advertising which online assumes the form of a banner, pop-up, link, image or true page, while in print newspapers it may even aspire to be a work of art. For some students print advertising is much more attractive than online advertising.

Even the reading styles of print and online newspapers are different. From a cognitive point of view, linear reading on print seems to require less cognitive effort than online, hyperlinked reading, which requires more decisions to be made and thus the use of more cerebral "real estate", to borrow the words of Coiro and Dobler (2007). These results echo those already available produced by other research projects (Burke and Rowsell, 2008; Leu et al., 2008; Mokhtari et al., 2009) which show that reading on print and digitally are diverse in terms of brain activation, contextual environment, cognitive focus, comprehension and reading speed. But the most important thing to stress is the fact that the style of reading of newspapers has profoundly influenced that of books: people increasingly read a book as if it were a newspaper. As Hillesund (2010) reports, today scholars seldom read articles and books, instead jumping around in the text, maybe reading only the conclusions or only the chapters and paragraphs that they found interesting.

Being different objects - one analogue and the other digital - print and online newspapers show a great diversity of use. Online newspapers offer only a use related to the bubble of functions designed for this digital object - all of these are immaterial. Print newspapers by contrast show many uses, which transcend that for which they have been expressively designed. Being material objects they lend themselves not only to immaterial but also to material uses. This may depend firstly on the fact that print newspapers are much older than online newspapers, so users have had more time to reinvent their design and thus to practise different uses; secondly and also in contrast to online newspapers, print newspapers are tangible, material objects, made of a particular type of 
paper, which is very versatile and recyclable, hence many different uses have developed over time and have become everyday habits for people.

The students' essays report many kinds of uses for print newspapers: as a covering to avoid dirtying the floor or the car seats; as wrapping for objects or gifts; to protect fragile or precious objects such as silver, glass or pottery; to transport containers of plants or flowers; to clean windows or kitchen equipment soiled from cooking food; to protect the floor during maintenance work; to fill bags and shoes to give them a shape; to speed up the ripening of fruit; to light a fire; to protect the furniture and floor whilst decorating; as bedding for pets; as protection against the cold and the wind when running or cycling in winter; to make sunhats. As seen from the ethnographic observation study, when print newspapers are abandoned on the train, they often become a shopping list or sheets of an album on which children's creativity is freely expressed. Some people also re-use the paper for artistic purposes: e.g. for making papier-mâché, necklaces, collage, earrings, hats and paper planes etc. In reality the print newspaper has also been a powerful source of artistic inspiration in the twentieth century, as the exhibition Shock of the News admirably illustrated (Brodie et al., 2012).

This list of material uses experienced by people shows how valuable the material support is to everyday life - the paper - of print newspapers and to how many practical uses this support has inspired people. Print newspapers are an excellent example of how people reshape and reinvent technologies through their use practice, since reading is generally the first use and may be followed by many others. Sometimes the chronology is different, as participant Mirko explains:

"For example, in my house I read news about Tangentopoli simply through discarding a component from a glass chandelier at home. It was exciting to discover the day (or period) in which it was wrapped and to re-read the news from that day."

The above examples of varied uses also show how articulated the lived experience of newspapers is. The diverse use of print newspaper helps us understand how profoundly newspapers are rooted in the folders of peoples' daily life. These observations speak for the persistence of print newspapers even though they are wide open to reshaping in the present highly digitalized media landscape. 
The reading styles described by our essay writers were very diverse. For example, participant Alice D.'s attention is more focused with print newspapers and more distributed with online newspapers. Articles in print newspapers show more analytical qualities and are more reliable than those online, furthermore, the reading of online newspapers is personal, reading print newspapers is more collective, whether at home or in public places such as bars or waiting rooms. Alice D. reports that she often reads a print newspaper in a train and leaves it on a seat to allow others to have it for free.

\subsection{Ritualization connected to the print and online newspapers}

According to Carey (1988) the transmission model fails to capture many dimensions of the practices of print newspaper use, such as the ritual functions of the media, which are important to understanding everyday life. Ritualization is especially important for print newspapers: in Italy the majority of customers buy their paper from a newsstand; subscriptions are a very limited component of sales.

The fact that people generally buy a print newspaper implies that they buy - or they read in a bar exactly the print newspaper that they like to read, that - according to Mirko - "mirrors their ideas". By contrast, when people read newspapers online Mirko continues, they more frequently read "news from many points of view, on the websites of different outlets, which leads to a more impartial reading”. Whilst this might be good for users, it can be a catastrophe for media groups. In fact according to participant Matteo, going online puts at risk the loyalty of the readership towards a specific outlet. It seems that online the functionality - reading the newspaper - is more important than the outlet. While the readers of the print newspaper have generated a consolidated ritualization of its reading as part of everyday life, the same has not happened with online newspapers which can be accessed everywhere and at any time. Hence, the different ritualization of the two practices of use has serious consequences for shaping different readership identities: the readership of print newspapers is generally a single and loyal audience, while that of online newspapers is multiple and unfaithful.

According to participant Francesca: 
"To be able to buy a print newspaper people have to leave the house, go to a newsstand and choose their favourite newspaper. Their choice may be influenced by several factors: their political ideology or simply a family habit; maybe it was the kind of newspaper that was read by their father or grandfather and that has become part of their family. Going to buy the newspaper on newsstands is also a pastime that many people do not want to give up, just think of the older people that you see at newsstands; for them it is not just a matter of going to buy a newspaper but it is a real ritual for overcoming loneliness, in fact at their newsstand they have the chance to chat with the newsagent and with all the people who are normally there. Thus we can say that the newspaper can also become a medium that allows people to be, to create a sort of meeting point where they can exchange views on the news they read in the newspaper, just consider all those elderly people whom you can see early in the morning if you go to have breakfast at your favourite bar, arguing passionately about politics and sports. Reading the print newspaper also means sharing it all together in a way that also builds a family ritual.”

This difference in ritualization also has unexpected effects on the reinvention by users of a newspaper's identity, for instance infrequent readers often treat a daily newspaper as a magazine.

As participant Serena writes:

"In my family, print newspapers are not thrown away the day after, because they include different types of information that last over time: a review of a book, for example, or the explanation of a scientific discovery or maybe some crosswords or other games. I also know that in other families it is the same: I have a friend who has the ritual to purchase Il Sole 24 Ore on Sunday. The Sunday edition is particularly rich in articles, insights, reflections and information. So, by reading it a little every day, she finishes reading it only the following Saturday.

5.4 Gestures and postures related to the reading of print and online newspapers

As Fortunati (2010) argued, in the attempt to reconstruct the phenomenology of Internet use, there has been a lack of attention to the gestures and postures which accompany the act of reading. The keyboard, positioned horizontally, concentrates the activity of writing in the same location as the 
tradition of writing on paper, while online reading has been concentrated vertically at the height of the screen and so in a completely new position for the reader. Electronic reading - on a desktop computer - requires people to raise their head. The head is upright whilst one looks at the screen. People reading on paper read from top to bottom, with the head bent, in the classic position of prayer.

"Online newspapers are read on screen with the page and the head of reader at the same level, which means that the reader is in an equal position in respect to the journalist. With print newspapers the head-down reading expresses readers' subjection to the journalist, and maybe reflection and trust.” (Mirko)

Raising the head in the shift from print to online newspapers has placed the reader in a position of parity with the writer: those who read on a screen symbolically position themselves on the same level as those who wrote the electronic text. The figure of the e-actor with their capacity for both reading and producing electronic text (the famous 'prosumer') could develop only with this change in the reading posture of the reader using electronic devices. This change of almost ninety degrees in head posture obviously could not but have consequences both at the cognitive and the emotional level.

But what is regarded as a novelty for online reading, is the rule for consumption of films. Director Jean-Luc Godard argued that the cinema screen must be at head-height, while television has to be watched by lowering the head. More precisely, use of the computer-Internet seems more similar to cinema use than to television use. The computer-Internet situates itself in the cultural heritage of cinema, not only because of the presence of a screen, as Manovich (2001) stresses, but also because of the user's posture, which is very similar. However, this picture is made more complex by the increased variety in the shapes of computer and television screens. For example, the posture of a laptop user is halfway between the head-bent and the head-raised. The television has now emigrated to the wall and is watched at head-height similar to the cinema screen. 
Also mobility brings changes. Whilst "reading online newspapers on a desktop computer is a headon reading” (Serena), mobility makes reading with the head held high impossible. Mobile media, both tablets and mobile phones, have reintroduced to electronic reading the posture of the more-orless lowered head. Not only postures but also gestures are affected in a different way by the online and the offline world as well as by the print world itself. For example, while reading a book requires micro-gestures of the arms, reading a print newspaper inspires a consistent opening of the arms at the height of the heart that mimics a broad opening towards the world. Reading a newspaper is in fact much more tiring physically than reading a book, because the gestures required are larger. The gestures are broad and start from the sternum, opening up expansively to the outside, showing also at a metaphorical level, that they express the largest opening to the world. Participant Mattia argues that "These gestures give readers a sensation of opening towards the object and of relying on it without restrictions”.

Reading a newspaper removes the defence posture of arms gathered in front of the trunk and makes the reader feel open to the world. When a person reads the news they are in a position in which news arrive directly at the heart. Perhaps this is one of the reasons why news has such an emotional structure and impact.

Barnhurst and Nerone (2001) recall that the form of print newspapers is connected to democratic civic culture. This strong relationship is mirrored also in the gestures required to read a print newspaper. By contrast, on smartphones or tablets a finger suffices for pressing the keyboard or touching the screen. From broad gestures with print newspapers we shift to micro, intimate, gestures with online newspapers, which are adapted for reading snippets of information on mobile media and for an on-the-go lifestyle.

However, as the ethnographic observational study shows, postures and gestures for reading newspapers (observed according to their amplitude, rigidity and direction) vary according to several factors such as changes of reading environment, support used, duration of reading, distance between the reader and the support and the purpose of reading (Table 1). 
Table 1. Main results from the first ethnographic study

\begin{tabular}{|c|c|}
\hline Duration of the observation & Average $=15$ minutes \\
\hline Age range of the observed & $\begin{array}{l}\text { Two children; } 8 \text { subjects between } 20 \text { to } 30 ; 11 \\
\text { subjects over } 30\end{array}$ \\
\hline Reading device & $\begin{array}{l}\text { The majority read print; two read newspapers on } \\
\text { a smartphone; two on a tablet and one, on a } \\
\text { laptop }\end{array}$ \\
\hline The observed postures & $\begin{array}{l}\text { Sitting, sitting with the legs crossed, walking, } \\
\text { standing, standing with the arms outstretched to } \\
\text { hold up the newspaper, standing with the arms } \\
\text { folded to hold the paper, putting a hand under the } \\
\text { chin and lifting the newspaper with the other, } \\
\text { every now and then adjusting the way the paper } \\
\text { is folded. }\end{array}$ \\
\hline The observed gestures & $\begin{array}{l}\text { Browsing, marking the line with the finger to } \\
\text { read, bringing the body to the newspaper or the } \\
\text { newspaper closer to the body, underlining, taking } \\
\text { notes. }\end{array}$ \\
\hline The observed gesture characteristics & Amplitude, softness and distance from the body. \\
\hline $\begin{array}{l}\text { Distance between the reading device and the } \\
\text { body }\end{array}$ & $\begin{array}{l}\text { Averages calculated by eye: } 35 \mathrm{~cm} \text { for those who } \\
\text { placed the newspaper on the table; } 45 \mathrm{~cm} \text { for } \\
\text { those who have held it up; } 55 \mathrm{~cm} \text { for those who }\end{array}$ \\
\hline
\end{tabular}


put the newspaper on the legs.

A gesture that has migrated from print to online newspapers is the typical gesture of leafing through a newspaper. When reading print newspapers, gestures are much more frequent than when we read online newspapers; they involve intensive movements of the hands and arms in the former, but mainly use of the fingers in the latter. Another aspect that emerged from the ethnographic observational study is that the distance from newspaper to reader is slightly less with a print newspaper than with a tablet or smartphone. Finally, gestures in private indoor environments were softer than in public spaces. Larger gestures were observed only in public spaces and only in three cases.

\subsection{Emotion, identity and memorization and the reading of print and online newspapers}

At first thought, the print newspaper, an object designed to last for one day, should not arouse an intense emotional effect and attachment in people. However, often the personal and social life of things reveals unexpected aspects (Appadurai, 1986). While cultural categories and the social system of objects (Baudrillard, 1970) act as the sources of their meaning, McCracken (1990) argues that there is another set of instruments such as rituals or forms of symbolic actions that add meaning to the object. As Douglas and Isherwood (1979: p. 74) have observed in their anthropological theory of the consumption of goods, things work as markers or classifiers.

Emotions can arise from various elements: 1) the content of the newspaper: news related to wars, natural disasters and crimes might be highly emotional; 2) the particular pleasure gained by the regular readers of a newspaper in recognizing in themselves in the ideological and political stance of the newspaper as well as in the opinions expressed by one or more of its journalists; this increases their sense of belonging to that specific readership; 3) the sensory channels involved in the interaction. The print newspaper, for example, conveys tactile sensations (related to a particular texture, roughness of pages), olfactory (many students report on the smell of the ink), auditory (the noise of the newspaper is also often reported) and visual (e.g. the specific layout of the newspaper 
that distinguishes it from others and that the reader recognizes as habitual, or the particular colour of the pages or how titles are highlighted in yellow in order to mimic a common practice of highlighting some words or sentences while reading on paper). The multisensory experience offered by a print newspaper represents an important aspect, which is pleasantness. This might be found also online, but here, as Lia Lucato, our expert interviewee, argues:

“... it derives mainly from the content, whereby it is another type of pleasure. In print you enter a certain atmosphere immediately, whilst with tablets, smartphones, computers which are rigid objects, users must respect certain procedures. In the online reading experience all activities tend to be traced to the mental experience, whilst reading in print multisensoriality obliges us to take into account that brain and mind are two different realities and that the latter is only a part of the former."

The context in which the reading of a newspaper takes place is also important. For example, participant Paolo talks about a sensation of coldness when reading online newspapers and a sensation of psychophysical well-being when reading print newspapers:

"Many people read print newspapers in bars. Indeed, the majority of them go to the bar expressly to read the newspaper: the cappuccino, the espresso, the brioche, the other customers are a pleasant framework to the reading of the newspaper. This entails a sensation of relaxation, a well-being which raises morale. Reading newspapers online does not entail the same sensation of bliss because there is not the same contact with the printed paper, there is not the human contact with the newsagent or with bartenders and patrons of the bar. One is alone with the online newspaper; there is no space for co-present sociability.

An online newspaper, however, while carrying fewer physical sensations, permits rich interaction owing to the presence of multimedia content e.g. audio, video, etc. An online newspaper is more convenient than the print newspaper particularly if read on a tablet or smartphone, and it can be constantly updated. Furthermore, through screenreaders even blind people can access its content, 
comment on it and share it. The emotional impact of newspapers is also dependent on the particular historical moment in which one considers it. For example, according to participant Alice A.:

“... when the printed newspaper was one of the few sources of information, the emotional impact of the news was different (it is important how news is presented and what importance is given to each piece of news)."

Participant Alice D. says that in print newspapers she searches for news and insights that enable her to transform the information into knowledge, while on the Internet she looks for more commentable news. The other important element is that physical contact with the print newspaper and thus the various sensory channels elicits more accessible memorization. She also adds that given the overload of online information, it is much difficult to memorize what she reads in online newspapers. This opinion is shared by participant Serena who adds that, particularly with a print newspaper, it is possible to understand something of the identity of a person, for example their political orientation, from seeing which type newspaper they read. However as participants Asia and Matteo emphasize, reading a print newspaper is still a sign of social distinction.

In this study the reading of print newspapers emerges as slow and relaxed while the reading of online newspapers is more hasty and tense. This does not mean that online reading is more rapid than print reading: on the contrary, as Dillon (1992) emphasizes, reading on a screen is twenty to thirty percent slower than on paper. Reading print newspapers is slower, argues participant Ares, because the reader is quieter and "this calm is the fruit of the defined space of the medium; one knows how much there is to read."

\section{Discussion and conclusive remarks}

The results of this study validates that our theoretical starting points - the physicality of online and offline newspapers; the decision to situate the research inside the micro-sociology of objects, new materialism framework, and immaterial labour theory - were feasible. 
The study produced many answers to the first research question, what are the main physical characteristics of the 'objects' print newspapers and online newspapers as they are perceived by users, that are in line with new materialism. Print newspapers as material objects are used to mark and stabilize social relations and daily activities. For this reason, they will hardly be replaced by online newspapers that are historically and socially less bound (Serres, 1995) The outside of a print newspaper, what Bennett (2010) called 'thing-power', drives users' attention towards its operationality, and is much stronger than that of digital newspapers. Furthermore, our microsociological analysis showed that Italian students perceive that printed newspapers 'do more things' and have more capacity to catalyse multisensoriality and co-present social events (such as reading together and sharing the newspaper). In summary, the results of the study clearly show that there is no equivalence between print and online newspapers. They are two different objects with which users have completely different experiences.

With respect to the second research question, what are the concrete practices of use of these two different newspapers, the study brought out several differences. The readerships of print and online newspapers have different degrees of freedom in their use practices with newspapers, different reading styles, emotion and effectiveness of memorization, as well as rituals. They also use different gestures and postures. In particular, our finding about postures and gestures opens new paths for future research. Findings show how the material characteristics of reading devices shape a reader's body; and how the human body mirrors the symbolic, cultural and social characteristics of the relationships between users, reading devices and journalistic contents. This also hints that reading print and online newspapers entails different types of immaterial labour. Printed newspapers trigger more social interactions and encounters - e.g. on the way to and at a newsstand, in the public reading place etc. - while online newspapers lead to more social participation and selfexpression.

Despite all of this, entire media groups sell these two very different products as if they were the same. Even the readers are not the same: Fortunati, Deuze and de Luca (2013) showed that people 
who read news frequently on only one platform make up less than a third of newspaper readers while those who consume news frequently on at least two platforms make up forty-four percent of newspaper readership. The strategy of replacing print newspapers with an online version applied by some media groups is therefore profoundly wrong and destined to fail. Recently, many corrective measures have been employed, such as the decision by Newsweek to re-launch a weekly print edition (Holpuch, 2013). Our research debunks the myth of the equivalence of print and online newspapers: they are two very different material objects. In this respect, our findings highlight the need to further develop the strategies that several publishers have already activated to tackle the current crisis facing the printed press. An example is providing alternative offerings and various paywall configurations.

Producing online newspapers instead of print newspapers is not a good solution to the crisis. The readers of print and online newspapers have a different ritualization, different degrees of freedom in their use practices with newspapers, different reading styles, different emotions, different effectiveness of memorization and they use different gestures and postures. Print newspapers as material artefacts should be developed to meet the needs of today's mobile and personal lifestyles. This might involve making print newspapers more readable on the move - e.g. by changing the size of newspapers - and including bridging elements - QR codes are the first thus far little used example of this - that maintain the physical properties of this highly valued artefact and add online conveniences and functionality to them.

To conclude, by investigating print newspapers as material objects this study has enriched the understanding of newspapers. It has moved the focus from the use of technical functionality to the physical properties, the public and users' physical practices. Whilst the majority of the existing research pays heed to the consequences of digitalization for professional practices in the newsroom it often ignores the readers. The readership represents - amongst the others - the most crucial economic factor, so it is critical for news media to understand deeply users' habits and try to address their needs and desires through a diversification of print and online products. 
The findings of this study can further be interpreted in the light of contemporary psycho-social perspectives. The importance of artefacts and their daily uses have been largely recognized, for example, by cultural psychology (Cole, 1996) and by social representations approach (Wagner and Hayes, 2005). Both argue that artefacts and their daily uses play the same role as daily discourse and common sense for cultural and representational analyses. For Cole, perception is culturally mediated and artefacts must be seen as mediators of reality as they are culturally shaped. This is especially relevant in the case of newspapers that mediate culturally bounded perceptions on multiple levels. These levels include the material and the immaterial reality, but in the case of online newspapers, these include also the first, second and third order of objects. From another perspective, Wagner and Hayes argue, by referring to Bourdieu's notion of habitus, that practices are related to behaviours, and behaviours to representations. This, in turn, reveals how knowledge is rooted in the materiality of everyday life.

\section{Limitations and future directions}

The limitations of this research are first and foremost related to its qualitative approach, which renders the results ungeneralizable. Secondly, it is without doubt that results relating to gestures, postures, ritualization and emotions need robust quantitative and cross-cultural studies. Thirdly, the study depends heavily on students' perceptions and is deeply rooted in the Italian context. The findings are dependent on Italian culture and reflect some common habits of Italian people, such as the socialization of the news in semi-public spaces like bars, cafes or public transport. Fourthly, there is a need to further develop ethnographic studies on postures and gestures in order to produce a holistic view of the practices of online and offline newspaper uses. Fifthly, it would be interesting to repeat the essay study and the ethnographic observational study in other countries to examine possible differences in the practices of newspaper use. Finally, as we mentioned, it would be worthwhile, to apply to print and online newspapers, a social representation study approach. The findings of this study could be used as a starting point. 


\section{References}

Alaimo S and Hekman S (eds) (2008) Material Feminism. Bloomington: Indiana University Press. Appadurai A (ed) (1986) The Social Life of Things: Commodities in Cultural Perspective. Cambridge: Cambridge University Press.

Arvidsson A and Colleoni E (2012) Value in Informational Capitalism and on the Internet. The Information Society 28(3): 135-150.

Barad K (2003) Posthumanist Performativity: Toward an Understanding of How Matter Comes to Matter. Signs: Journal of Women in Culture and Society 28( 3): 801-31.

Barad K (2007) Meeting the Universe Halfway: Quantum Physics and the Entanglement of Matter and Meaning. Durham, N.C.: Duke University Press.

Barnhurst KG and Nerone J (2001) The Form of News. A History. New York: The Guilford Press.

Baron N. (forthcoming) Words Onscreen: The Fate of Reading in a Digital World. Oxford: Oxford University Press.

Barrett E and Bolt B (eds) (2013) Carnal Knowledge: Towards a 'New Materialism' through the Arts. London: Tauris.

Baudrillard J (1988) [1970] Consumer Society, in M. Poster (ed) Selected Writings. Cambridge: Polity Press.

Bennet J (2010) Vibrant Matter: A Political Ecology of Things. Durham: Duke University Press.

Bennett T and Joyce P (2010) Material Powers: History, Culture and the Material Turn. New York: Routledge.

Boczkowski PJ (2004) Digitizing the news: Innovation in online newspapers. Cambridge, MA: The MIT Press.

Brodie J, Boxer S, Mileaf J, et al. (2012) Shock of the news. Washington: National Gallery of Art.

Burke A and Rowsell J (2008) Screen pedagogy: Challenging perceptions of digital reading practices. Changing English: Studies in Culture \& Education 15(4): 445-456. 
Casetti F (ed) (1995) L'ospite fisso. Televisione e mass media nelle famiglie. Milano: San Paolo Edizioni.

Coiro J and Dobler E (2007) Exploring the online reading comprehension strategies used by sixthgrade skilled readers to search for and locate information on the Internet. Reading Research Quarterly 42(2): 214-257.

Cole M (1996) Cultural Psychology: A once and future discipline. Cambridge: Harvard University Press.

Colombo F (2013) “Dalla mobilitazione televisiva del 1968 a quella informatica del 2013", lectio magistralis held at the course in Multimedia Sciences and Tecnologies of the University of Udine, Pordenone, April 10, 2013.

Coole DH and Frost S (2010) New Materialisms: Ontology, Agency, and Politics. Durham, N.C.: Duke University Press.

Cull BW (2011) Reading revolutions: Online digital text and implications for reading in academe. First Monday 16(6).

Della Porta D (2010) L’intervista qualitativa. Roma: Laterza.

Deuze M (ed) (2011) Managing media work. London: Sage.

Dillon A (1992) Reading from paper versus screens: A critical review of the empirical literature. Ergonomics, 35(10): 1,297-1,326.

Dolphijn R and Van der Tuin I (2012) New Materialism: Interviews \& Cartographies. Ann Arbor: Open University Press - University of Michigan Library.

Domingo D (2008) Interactivity in the daily routines of online newsrooms: dealing with an uncomfortable myth. Journal of Computer-Mediated Communication, 13: 680-704.

Douglas M and Isherwood B (1979) The World of Goods: Toward an Anthropology of Consumption. London: Allen Lane.

Fortunati L (2007) Immaterial Labor and its Machinization. Ephemera. Theory \& Politics in Organization 7(1): 139-157. 
Fortunati L (2010) Some Thoughts about Electronic Texting, paper presented at the ESF-COST workshop “Electronic Textuality”, 15-16 June 2010, Istanbul, Turkey.

Fortunati L, Sarrica M, Balcytiene A, et al. (2009) The influence of the Internet on European journalism. Journal of Computer-Mediated Communication 14: 928-963.

Fortunati L, Deuze M and de Luca F (2013) The News About News: How Print, Online, Free, and Mobile Coconstruct New Audiences in Italy, France, Spain, the UK, and Germany. Journal of Computer-Mediated Communication, Article first published online: 20 MAY 2013 | DOI: $10.1111 / j c c 4.12017$

Fuchs C (2010) Labour in Informational Capitalism and on the Internet. The Information Society 26(3): 179-196.

Hillesund T (2010) Digital reading spaces: How expert readers handle books, the Web and electronic paper. First Monday 15(4).

Holpuch A (2013) Newsweek to print weekly edition again one year after calling it quits. The Guardian, Wednesday 4 December. Accessed 12 January 2013 at http://www.theguardian.com/media/2013/dec/04/newsweek-to-print-weekly-again

Katz E, Blumler JG, and Gurevitch M (1973-1974) Uses and Gratifications Research. The Public Opinion Quarterly 37(4): 509-23.

King N and Horrocks C (2010) Interviews in Qualitative Research. London: Sage.

Komter A (2001) Heirlooms, Nikes and Bribes: Towards a Sociology of Things. Sociology 35(1): $59-75$.

Küng L, Picard R, and Towse R (eds) (2008) The Internet and the Mass Media. London: Sage.

Leu DJ, Coiro J, Castek J, et al. ( 2008) Research on instruction and assessment in the new literacies of online reading comprehension. In C. Collins Blok and S.R. Parry (eds) Comprehension instruction: Research-based best practices. New York: Guilford Press, pp.321-342.

Manovich L (2001) The Language of New Media. Cambridge, Mass: MIT Press. 
Massing M (2002) When watchdog meets lapdog, Columbia Journalism Review, 4 June 2012, accessed $3 / 2 / 2014$

at http://www.cjr.org/the_kicker/when_watchdog_meets_lapdog.php?page=all

McCracken G (1990) Culture and Consumption. Bloomington and Indianapolis: Indiana University Press.

Miller D (1998) (ed) Material Cultures: Why Some Things Matter. Chicago: University of Chicago Press.

Mokhtari K, Reichard CA and Gardner A (2009) The impact of Internet and television use on the reading habits and practices of college students. Journal of Adolescent \& Adult Literacy 52(7): 609-619.

Ostrower F (1998) Nonparticipant observation as an introduction to qualitative research. Teaching Sociology, 26(1), 57-61.

Sarrica M, Fortunati L and Balcytiene A, et al. (2010) The Integration of the Internet in European Newsrooms. European Journal Of Communication 25(4): 413-422.

Schiff F (2013) Business models of news Web sites: A survey of empirical trends and expert opinion, First $\quad$ Monday $\quad$ 3(6), accessed 2014 at http://firstmonday.org/issues/issue8_6/schiff/index.html

Serres M (1995) Genesis. Ann Arbor: University of Michigan Press.

Turkle S (2007) Evocative Objects: Things We Think With. Cambridge, MA: MIT Press.

van der Wurff R and Lauf E (eds) (2005) Print and online newspapers in Europe: A comparative analysis in 16 countries. Het Spinhuis, Amsterdam.

Wagner W. and Hayes N (2005) Everyday Discourse and Common Sense. The Theory of Social Representations. Basingstoke: Palgrave.

Wyatt S, Henwood F, Miller N, et al. (eds) (2000) Technology and In/equality: Questioning the Information Society. London: Routledge. 
The authors of the essays analyzed here are the following students: Alice Aste, Marco Balbinot, Serena Chiara Beddini, Matteo Chini, Arianna Cristaldi, Alberto Dal Santo, Matteo Da Ros, Daniele D’Attanasio, Alice De Benetti, Paolo Furlan, Mirko Privitera, Silvia Scandurra, Marco Sericola, Ares Daniel Spinella, Mattia Spizzo, Asia Stefanizzi, Andrea Vanon, Francesca Verde, Enrico Zonta. They are also the authors of the research projects illustrated in this manuscript. Although in general the essays are reported in an anonymized way, in these essays the students expressed the desire to be cited with their name and surname.

ii A European network of scholars (FP1104 New possibilities for print media and packaging: combining print with digital) has been promoted and funded in order to carry out the state of art of experiments, projects and research studies in Europe on these themes. 